
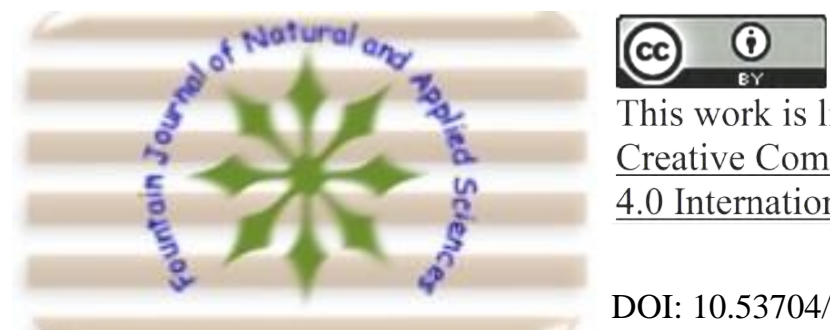

This work is licensed under Creative Commons Attribution 4.0 International License.

DOI: $10.53704 /$ fujnas.v8i2.282

A publication of College of Natural and Applied Sciences, Fountain University, Osogbo, Nigeria. Journal homepage: www.fountainjournals.com ISSN: 2354-337X(Online),2350-1863(Print)

\title{
Development of an Intelligent Pipeline Vandalism Detection and Reporting System
}

\author{
${ }^{* 1}$ Azeez, R. A. and ${ }^{2}$ Akinlolu, A. O. \\ ${ }^{I}$ Department of Mathematical and Computer Sciences, Fountain University, Osogbo, Nigeria \\ ${ }^{2}$ Information and Communications Technology Unit, Fountain University, Osogbo, Nigeria
}

\begin{abstract}
Leaks in pipelines due to vandalism have always been a great concern due to loss of life, the implied risks and its associated costs. This has become even more critical with hazardous fluids that pose risk to life and the environment. In view of this, leak-detection systems play an important role in safeguarding pipeline operation by helping operators to quickly identify and react to spills. This paper aims to develop and demonstrate the use of an Intelligent Pipeline Vandalism Detection and Reporting System (IPVDRS) in detecting possible vandalism of petroleum pipelines in our environments. The system was developed using Visual Basic.NET technology. The system was able to interpret the readings of the remote sensors on the pipeline, detects compromise and trigger an alarm, creating the GPS coordinates of the triggered sensor on a map.
\end{abstract}

Keywords: Vandalism detection, Gas pipelines, Vibration threshold, Report system

\section{Introduction}

Nigeria's oil industry has increased activities in the past 40 years (Udofia \& Joel, 2012). Oil companies are battling against rising vandalism, costing an estimated 300,000 barrels of crude a day (Anifowose et al., 2012; Obenade \& Amangabara, 2014; Boris, 2015). The stolen oil fuel is a lucrative black-market business in Nigeria (Albert et al., $2019)$. With the rise in global oil price above $\$ 100$ a barrel in the early 2000s, the theft of oil became a very lucrative business. This was occasioned by lack of youth employment in the region, many of the Niger Delta unemployed indigenes took to the illicit hydrocarbon trade (i.e. small-scale tapping of crude oil, petroleum theft/smuggling and artisanal refining) as a source of income (Evans \& Kelikume, 2019).

As the African's top oil exporter, Nigeria has faced unprecedented challenges concerning losses in production occasioned by incessant vandalism of crude oil pipelines (Ambituuni et al., 2014). The country is losing about 300,000 barrels of crude daily to oil vandalism, worth over $\$ 3.65$ million annually (Anifowose et al., 2012; Boris, 2015; Obenade \& Amangabara, 2014; Albert et al., 2019).

The resultant effect of incessant vandalism ultimately leads to loss of resources, insecurity, fall

*Corresponding author: +2348034105858

Email address: ajeazeez@gmail.com 
in oil revenue, poor financing of development projects etc., thereby affecting Nigeria's development programmes (Wilson, 2014). Without adequate provision for the prompt reporting of pipeline damage due to vandalism by unscrupulous individuals, or due to inadequacy of available countermeasures, problems such as oil explosion, environmental pollution, equipment damages, fuel scarcity and loss of investors who patronize the oil and gas business persist.

In 2013, Nigeria - Africa's largest oil producer, suffered severe attacks on its critical export pipeline system leading to the loss and deferment of about 300,000 barrels/day (Obenade \& Amangabara, 2014; Boris, 2015). This deferred production is equivalent to the total production of Equatorial Guinea and larger than the entire production of Ghana, Congo Brazzaville, Cameroun and Gabon (Obenade \& Amangabara, 2014).

Generally speaking, failure in pipelines could be due to corrosion and wear tear on pipelines, intentional damage and sabotage, design errors or in operations outside design limits and degradation of pipelines due to environment effects (Heidary \& Groth, 2019).

Out of all these causes of pipeline leaks, intentional damage or sabotage is the order of the day in Nigeria and is more prevalent in oil-rich states in south-south Nigeria. This is more escalated by support from syndicates and highly support influential unscrupulous elements and unemployed youths, who see this dastardly acts more of a booming trade without regard to its damaging consequences (Ozoigbo, 2019).

Efforts have been made in various studies in detecting and reporting pipeline vandalism, many among others is the study of Yazdekhasti, Piratla, Atamturktur, and Khan (2018), in this study, an experimental evaluation of a vibration-based leak detection technique for water pipelines was carried out, which involves continuous monitoring of the change in the cross-spectral density of surface vibration measured at discrete locations along the pipeline. The results revealed the potential feasibility of the proposed technique to detect and assess the onset of single or multiple leaks in a complex system.
Also, in the study of Ekeke (2019), a transient compressible natural gas flow through a pipeline was studied by the use of a finite volume method in 2D axis-symmetric cylindrical coordinates. To account for turbulence within the pipeline system, the standard turbulence model was simulated together with the Navier Stokes System of equations via the Reynolds-Averaged method. The equation of state-employed was the Soave-RedlichKwong equation. Implicit discretization was used for the temporal terms, whereas the central differencing scheme and the upwind differencing scheme were used in the discretization of the spatial diffusion terms and the spatial convection terms respectively. The Pressure Implicit with Splitting of Operators (PISO) algorithm was then used for calculating the pressure and velocities on a staggered grid. A computer simulation was carried out to determine variations in pressure, density, velocity and temperature within the pipeline system. Profiles for turbulence viscosity, turbulence kinetic energy and turbulence eddy dissipation along the pipeline were also obtained. The method, therefore, can become an invaluable tool and template for use by the oil and gas industry for mitigating the consequences of pipeline perturbations such as vandalism explosions and ruptures by its application in leak detection systems.

Mawalkar et al. (2019) measured the leak of petroleum products using optical fibres based on Distributed Temperature System (DTS). The DTS is based on a principle of an optical reflectometer, i.e. the light impulse is transmitted to the fibre, part of the impulse returns to the detector due to optical scattering. The phenomenon of the returning part of the light impulse is called the Stimulated Raman Scattering. The DTS can measure temperature along the entire length of the fibre in real-time. We can imagine a thousand sensors along the measured track with the accuracy of 1 meter. In this case, we have an optical cable laid down along the testing polygon. This testing polygon is intended to simulate the transport of the oil products in the pipelines. Many different leaks are simulated here. The measuring is based on the volatility of petroleum products and their ability to evaporate. 
The surface of the object, from which the oil evaporates, decreases in temperature. Sudden change in temperature at a given point detects a possible leakage of petroleum products. This leak can be immediately pinpointed with the accuracy of one (1) meter and a necessary intervention can be performed.

Furthermore, Cintra de Oliveira \& Mintchev (2019) proposed a novel pipeline, this concept builds on the already existing pipe-in-pipe design by segmenting the pipeline system with segmentation rings and embedding a linear wireless network in the annular air gap between the two pipe layers. Presence of fluid in the case of leakage into the pipeline space causes degradation of the wireless network to a point of interrupting the communication in a particular pipeline segment well before any external leak occurs. Thus, the internal leak is detected in real-time by an external central unit connected to the linear wireless network,

Most research efforts focus on the need to protect oil pipelines by deploying various methods and technologies as 24-hour routine surveillance, alarm systems and integration of better quality instruments. Other methods include noise detection system associated with pipeline leaks, acoustic wave alert monitor (Abdullahi \& Oyadiji, 2019).

Despite various technologies, strategies and studies being implemented for monitoring and reporting pipeline vandalism, this threat persists. This study, therefore, aims to develop and demonstrate the use of an Intelligent Pipeline Vandalism Detection and Reporting System (IPVDRS) in detecting possible vandalism of petroleum pipelines in our environment which is expected to go a long way in reducing pipeline vandalism in the country.

To the best of our knowledge and from available literature, none of the techniques adopted or suggested was able to detect pipeline leaks or vandalism which could automatically read the coordinates of the actual locations of leaks and report it in real time for necessary actions.

This study, therefore, is based on setting a benchmark as the threshold for pressure reading, such that any reading at variance within the threshold or a significant change in the pressure gradient is reported and an alarm system is triggered immediately for necessary actions.

\section{System Methodology}

The Database Management System (DBMS) deployed for IPVDRS is a Microsoft Access and its graphical user interface offers easy functionality and integration with .NET compared to other bigger DBMS such as MYSQL, MS-SQL, etc. While the programming language deployed for controlling the automation of the system as well as providing user interface is Visual Basic.NET which is an event-driven programming language from Microsoft implemented on the .NET framework.

The developed IPVDRS was used to simulate threshold values received from the sensors installed on the pipelines to detect changes in pressure and possible attacks on oil pipelines, for the reason that real-life pipeline approach was not achievable due to the sensitivity and security put in place on the pipeline routes in our locals. Sensors are placed at about $1 \mathrm{~km}$ interval on the pipeline since the transient pressure wave travel at a speed of over 1 kilometer in 5 seconds for gases and a little less for liquids.

\section{System Design}

The Intelligent Pipeline Vandalism Detection and Reporting System was designed to collect data from remote sensors placed at $1 \mathrm{~km}$ intervals on the gas pipelines, the geographical location of the sensors (i.e. the longitude and latitude coordinates) will be recorded in the system's database during installation.

Pressure reading data will be sent through an internet gateway device located on the pipeline site. IPVDRS was configured to read the sensor pressure data while the sensitivity of damages on the pipelines was set to decide which pressure reading values should trigger an alarm.

If the pipeline pressure reading sent by one of the sensors surpasses the set threshold, then this indicates the presence of leakages and vandalism. At this stage, an alarm is triggered by the IPVDRS. The system user can confirm the occurrence of any form of vandalism by checking the satellite map of the pipeline location. 
Figure 1 represents the system architecture for the Intelligent Pipeline Vandalism and Reporting System. The database tables of IPVDRS are as shown in Table 1, 2 and 3. Figure 2 shows the user's interaction and the relationship between IPVDRS use cases which could be involved. While Figure 3 depicts the flowchart of the IPVDRS.

Table 1: User Table Database Structure

\begin{tabular}{lll}
\hline FIELD NAME & DATA TYPE & FIELD SIZE \\
\hline ID & Numeric & 20 \\
Username & Text & 20 \\
\hline Password & Text & 50 \\
\hline
\end{tabular}

Table 2: Sensor Table Database Structure

\begin{tabular}{lll}
\hline FIELD NAME & DATA TYPE & FIELD SIZE \\
\hline ID & Numeric & 20 \\
Latitude & Numeric & 20 \\
\hline Longitude & Numeric & 20
\end{tabular}

Table 3: Report Table Database Structure

\begin{tabular}{lll}
\hline FIELD NAME & DATA TYPE & FIELD SIZE \\
\hline ID & Numeric & 10 \\
Sensor ID & Numeric & 20 \\
Pressure & Numeric & 50 \\
Date & Text & 30 \\
\hline Location & Text & 30
\end{tabular}

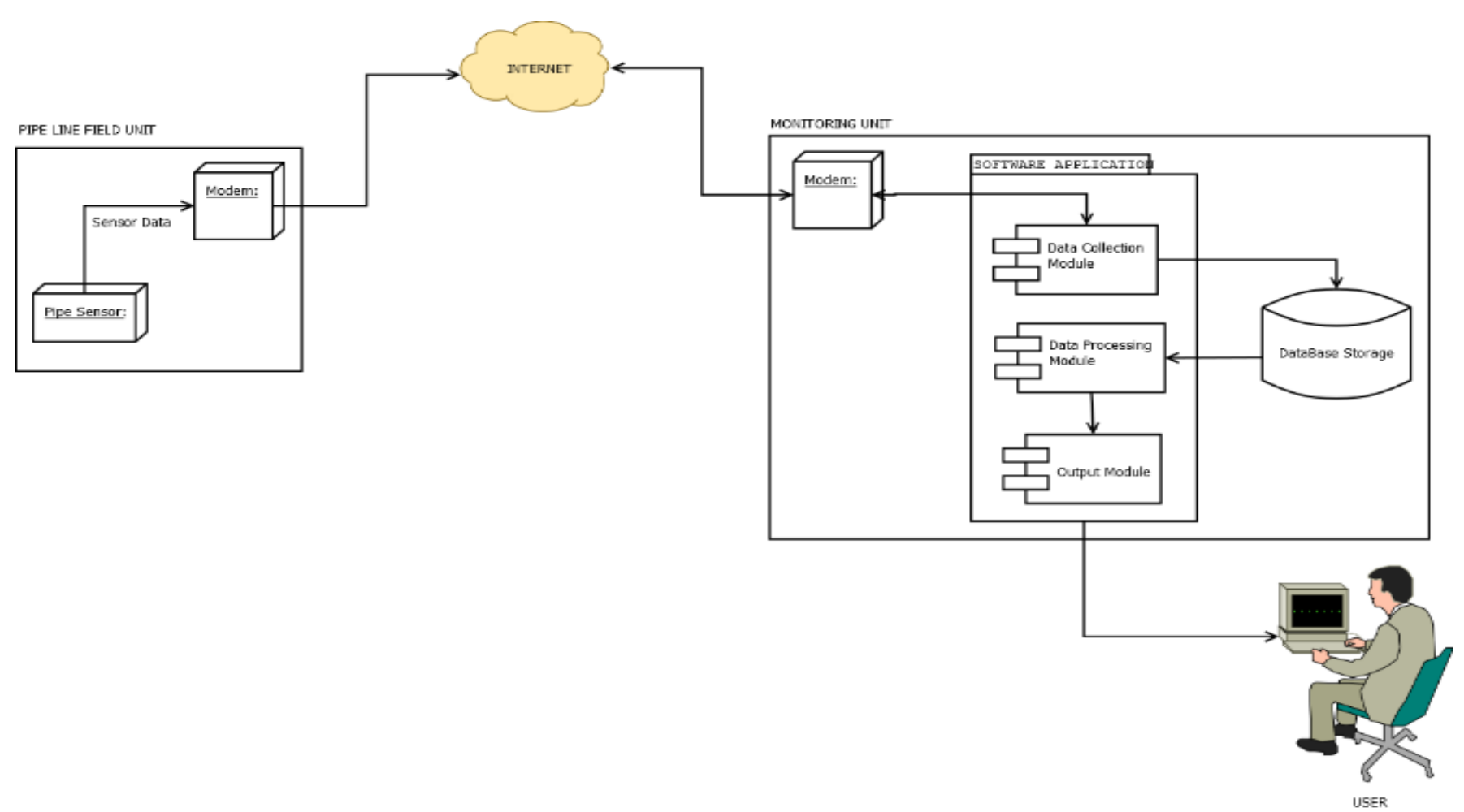

Figure 1: System Architecture for the Intelligent Pipeline Vandalism and Reporting System

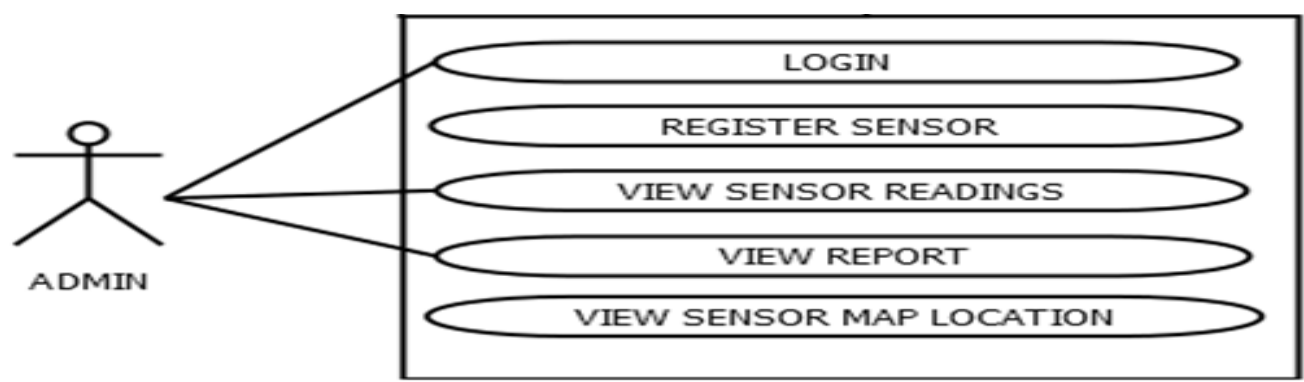

Figure 2: Intelligent Pipeline Vandalism Reporting System Use Case Diagram 


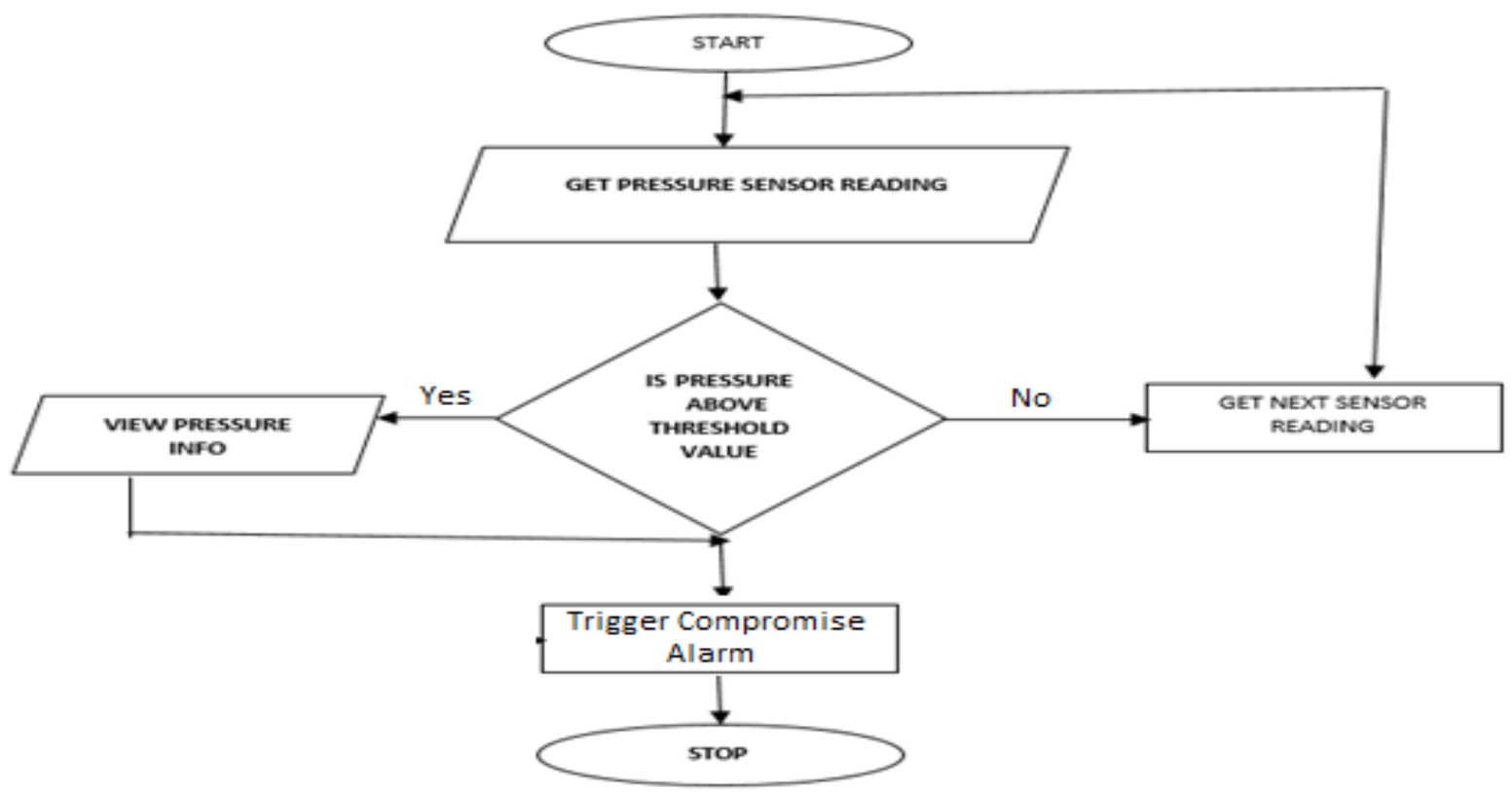

Figure 3: Intelligent Pipeline Vandalism Reporting System Flowchart Diagram

\section{Implementation and Results}

All user interface was designed using the Visual Basic.NET programming language. Figure 4depicts a System login page required to authenticate users into the system. This page provides a layer of authentication for the IPVDRS so that only authorized users can gain access.

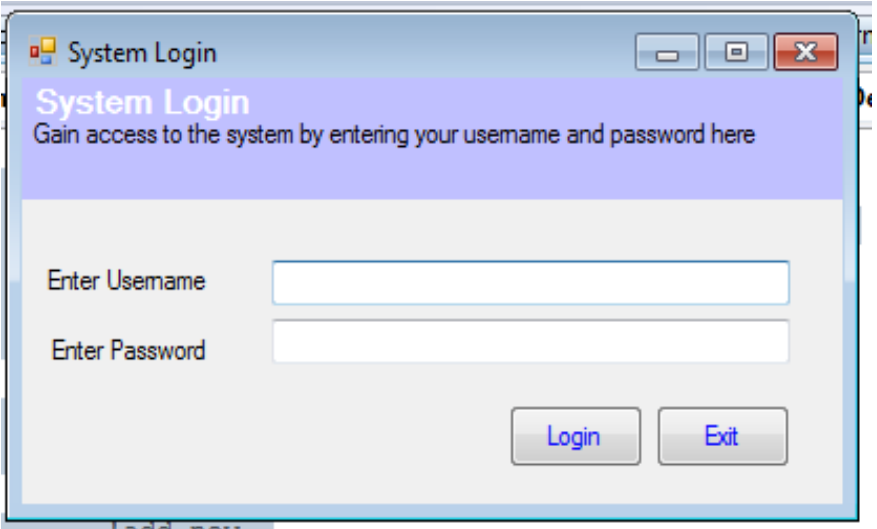

Figure 4: IPVDRS Login Page

Figure 5 shows adding of sensors and other information on the IPVDRS. Other information such as the geographic coordinates of the sensors that will be installed along the oil/gas pipelines.

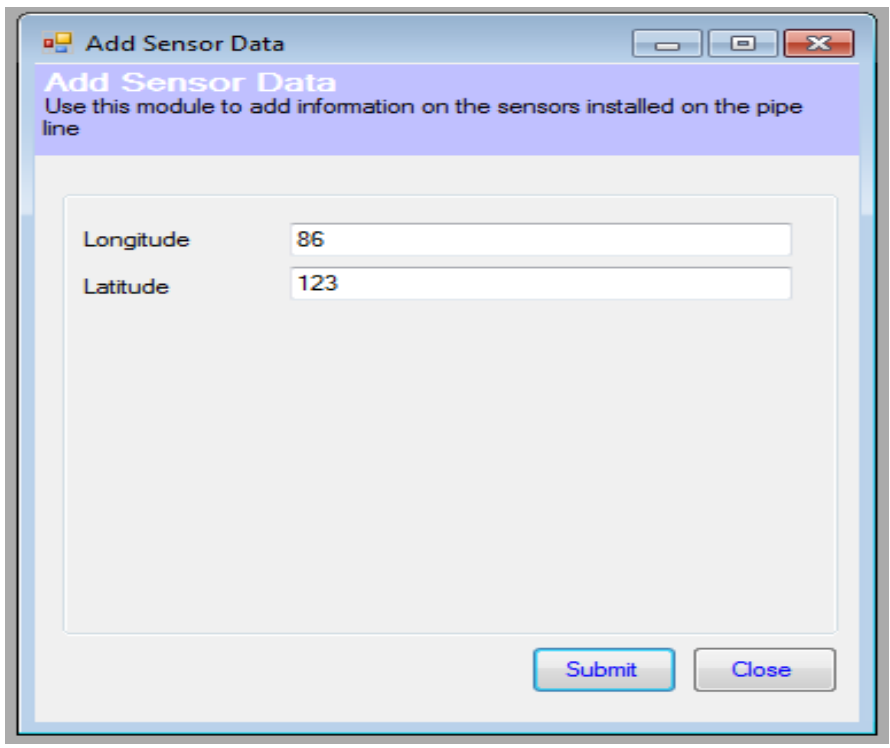

Figure 5: Adding Sensor on IPVDRS

As shown in Figure 6, the pressure threshold of IPVDRS was set in Inches of Mercury $(\mathrm{Hg})$, this is the maximum value that could be attained to trigger pipeline vandalism alert. That is, if the readings from any of the sensors return a gas pressure greater than this value, then the IPVDRS will alert the users for possible pipelines' leakage or vandalism. 
Fountain Journal of Natural and Applied Sciences 2019; 8(2): 21-27

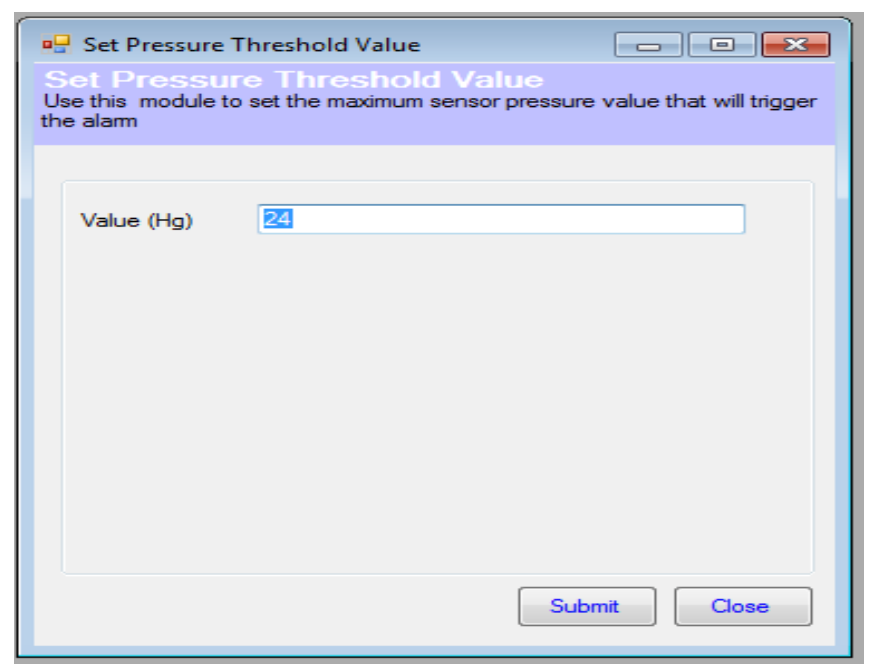

Figure 6: Setting Pressure Thresholds

As shown in figure 7, each sensor on the pipeline was simulated to generate the readings (pressure values). The "Start Sensor Reading Simulation" button begins the simulation.

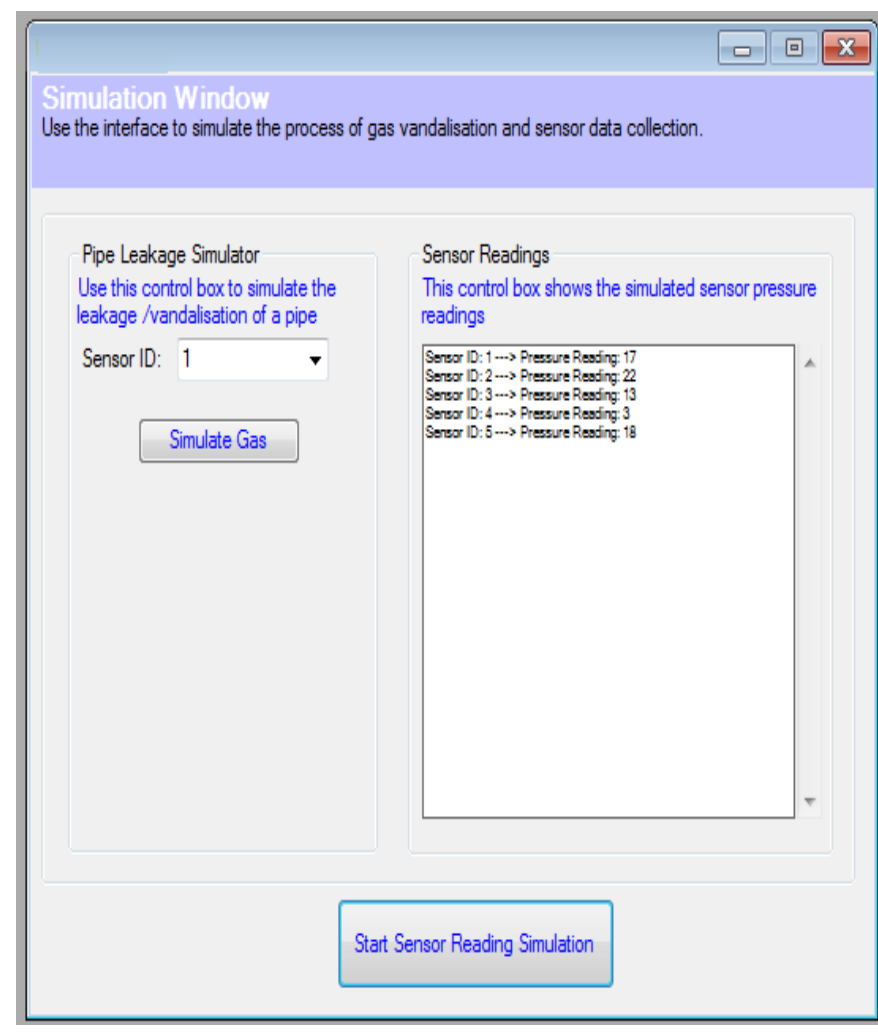

Figure 7: IPVDRS Simulation

The simulation of a gas leakage was performed on the sensor with ID number 2. This was done by clicking on the "Simulate Gas Leakage" shown in figure 8. Notification of possible pipeline vandalism was received.

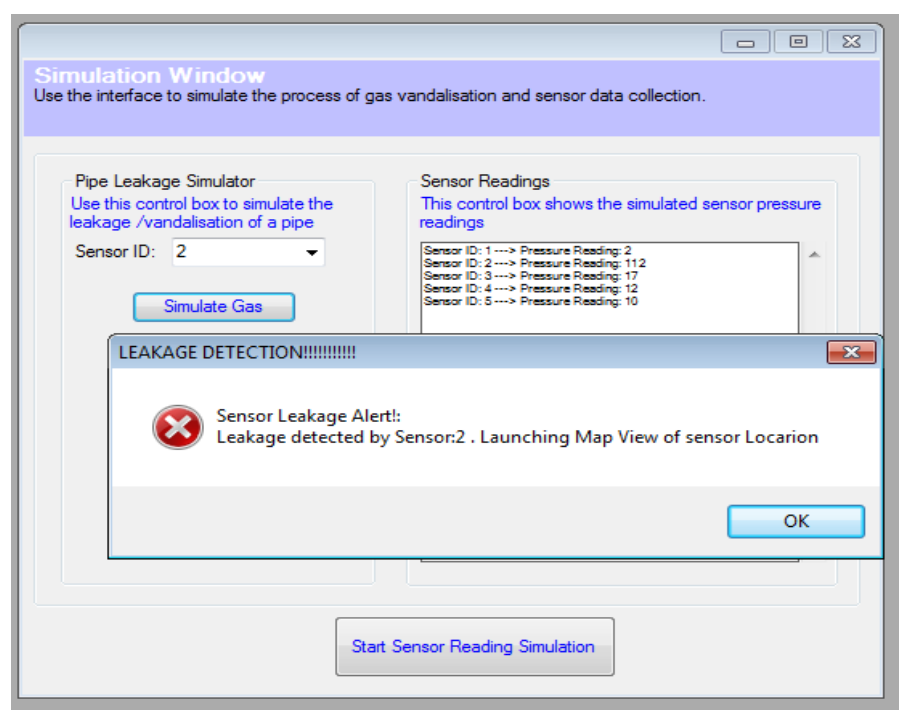

\section{Figure 8: IPVDRS leakage notification}

After receiving an alert from IPVDRS, the realtime geographic location of the alerting sensor, that is, the location of the pipeline that was vandalized was shown in figure 9.

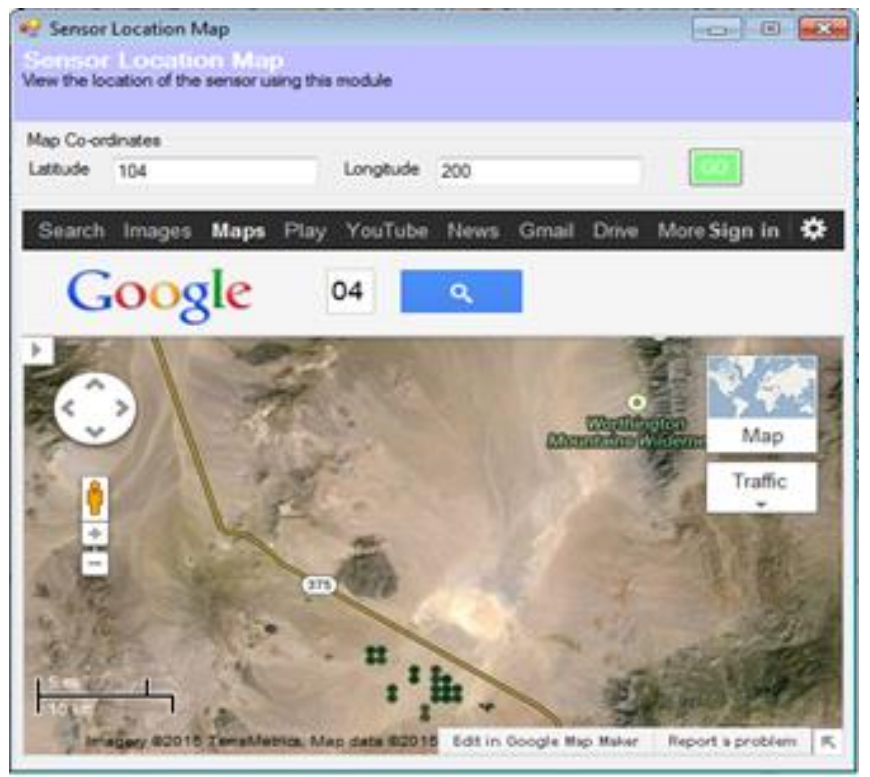

Figure 9: Map coordinates of vandalized pipeline location

\section{Conclusion \& Recommendation}

The results of the simulations carried out by the intelligent detection and reporting system show that a real-life implementation can yield positive results in detecting pipelines vandalism which has claim so many lives and increased lucrative black-market business in Nigeria. 
This paper presents an information system, providing useful information on vandalized locations, a solution to help in the management of petroleum product supplies.

Applying for this research work in the oil and gas sector of Nigeria could go a long way in reducing pipeline vandalism since these pipeline routes are poorly secured without adequate surveillance system, thereby making them targets of repetitive attacks by Vandals.

\section{References}

Abdullahi, M. \& Oyadiji, S. O. (2019). Simulation and experimental measurement of acoustic wave reflectometry for leak detection in pipes. Proceeding SPIE 10972, Health Monitoring of Structural and Biological Systems XIII. doi: $10.1117 / 12.2528686$.

Albert, O., Amaratunga, D. \& Haigh, R. (2019). An investigation into root causes of sabotage and vandalism of pipes: A major environmental hazard in Niger Delta, Nigeria. In ASCENT Festival 2019: International Conference on Capacity Building for Research and Innovation in Disaster Resilience 22-37. National Science Foundation of Sri Lanka.

Ambituuni, A., Amezaga, J. \& Emeseh, E. (2014). Analysis of safety and environmental regulations for downstream petroleum industry operations in Nigeria: Problems and prospects. Environmental Development 9, 43-60.

Anifowose, B., Lawler, D. M., Van der Horst, D. \& Chapman, L. (2012). Attacks on oil transport pipelines in Nigeria: A quantitative exploration and possible explanation of observed patterns. Applied Geography 32(2), 636-651.

Boris, O. H. (2015). Upsurge of oil theft and illegal bunkering in the Niger Delta region of Nigeria: is there a way out?. Mediterranean Journal of Social Sciences 6 (3), 563-573. doi:10.5901/mjss.2015.v6n3s2p563

Cintra, R. J., de Oliveira, T. V. \& Mintchev, M. P. (2019, November). Wireless Network for RealTime Detection of Pipeline Leakages. In 2019 Big Data, Knowledge and Control Systems Engineering (BdKCSE) (pp. 1-5). IEEE.

Ekeke, I. C. (2019). Simulation of Unsteady State Flow of Natural Gas in Pipelines Using Finite
Volume Method in 2d Cylindrical Coordinates (Doctor of Philosophy in Chemical Engineering), Federal University of Technology, Owerri, Nigeria.

Evans, O. \& Kelikume, I. (2019). The impact of poverty, unemployment, inequality, corruption and poor governance on Niger Delta militancy, Boko Haram terrorism and Fulani Herdsmen attacks in Nigeria. International Journal of Management, Economics and Social Sciences (IJMESS), 8(2), 58-80.

Heidary, R. \& Groth, K. M. (2019). A hybrid model of internal pitting corrosion degradation under changing operational conditions for pipeline integrity management. Structural Health Monitoring. 1-17. doi: 10.1177/1475921719877656

Mawalkar, S., Brock, D., Burchwell, A., Kelley, M., Mishra, S., Gupta, N. \& Shroyer, B. (2019). Where is that CO2 flowing? Using Distributed Temperature Sensing (DTS) technology for monitoring injection of $\mathrm{CO} 2$ into a depleted oil reservoir. International Journal of Greenhouse Gas Control 85, 132-142.

Obenade, M. \& Amangabara, G. T. (2014). Perspective: The environmental implications of oil theft and artisanal refining in the Niger Delta Region. Asian Review of Environmental and Earth Sciences 1(2), 25-29.

Ozoigbo, B. I. (2019). Insecurity in Nigeria: genesis, consequences and panacea. European Journal of Social Sciences Studies 4(9), 270281. doi: 10.5281/zenodo.3531844

Udofia, O. O. \& Joel, O. F. (2012). Pipeline Vandalism in Nigeria: Recommended Best Practice of Checking the Menace. Paper presented at the Nigeria Annual International Conference and Exhibition, Lagos, Nigeria. (pp. 1-8). https://doi.org/10.2118/162980-MS

Wilson, G. (2014). The Nigerian state and oil theft in the Niger Delta region of Nigeria. Journal of Sustainable Development in Africa 16(1), 69-81. Yazdekhasti, S., Piratla, K. R., Atamturktur, S. \&

Khan, A. (2018). Experimental evaluation of a vibration-based leak detection technique for water pipelines. Structure and Infrastructure Engineering 14(1), 46-55. doi:10.1080/15732479.2017.1327544 